\title{
doispontos:
}

\section{Merleau-Ponty leitor de Freud}

\author{
Alex Moura \\ Universidade de São Paulo
}

Resumo: Este artigo busca tematizar o modo pelo qual Merleau-Ponty estabelece uma reflexão e um diálogo sobre Freud já em suas primeiras obras, especialmente em A Estrutura do comportamento e a Fenomenologia da percepção. Concentrando-nos, sobretudo, na problematização da noção de inconsciente e, com ela, do estatuto da consciência, o que se pretende mostrar é como o filósofo, ao mesmo tempo que recusa certa perspectiva de leitura do pensamento freudiano, aproxima-se e recorre a ele por meio de um horizonte próprio de compreensão. Isso nos permitirá, ainda, problematizar uma linha de interpretação crítica a respeito de sua apropriação do pensamento psicanalítico.

Palavras-chave: Merleau-Ponty; Freud; inconsciente; consciência; estrutura; sexualidade.

Abstract: This article intends to show how Merleau-Ponty establishes a reflection and a dialogue about Freud already in his first works, especially in The Structure of Behavior and in Phenomenology of Perception. Concentrating our focus on his concept of unconscious, and, with it, on the concept of conscious, what we want to show is how the philosopher, at the same time that refuses a specific perspective of reading Freud's thought, gets close to him by proposing another perspective of comprehension. This will allow us, at the same time, to discuss a critic interpretation about his psychoanalysis reading.

Keywords: Merleau-Ponty; Freud; unconscious; conscious; structure; sexuality

A discussão de Merleau-Ponty com Freud é mais rica e profunda do que se poderia supor em um primeiro momento. Há, nos escritos do filósofo, uma constante referência ao autor, embora seu caráter aparentemente esparso possa contribuir, em uma apreciação apressada, para a impressão de certa dispersão. O que procuraremos mostrar, ao contrário, é a coerência e a articulação dessas referências, explicitando a importância e o papel que elas assumem para as formulações de Merleau-Ponty. Para isso, nos concentraremos nos primeiros textos do filósofo, especialmente em A Estrutura do Comportamento e a Fenomenologia da percepção. Como se sabe, um dos momentos em que essa discussão ganha mais ênfase, do ponto de vista que será aqui proposto, é nos cursos sobre a instituição. Justamente por isso, o que propomos neste ensaio é uma espécie de prenúncio ou de antecipação, buscando explicitar como essa questão já se faz presente e adquire relevância desde o início do pensamento de Merleau-Ponty, revelando a importância da problematização da psicanálise no interior de sua reflexão já em um momento comumente pouco considerado por seus leitores.

Devido à amplitude desse diálogo, é necessário um recorte, a fim de podermos acompanhá-lo através de um de seus aspectos principais. Aqui, procuraremos fazê-lo por meio da discussão sobre o estatuto do inconsciente e, com ele, da consciência, explicitando o modo pelo qual o filósofo, ao mesmo tempo que recusa certa perspectiva de leitura do pensamento freudiano, aproxima-se e recorre a ele por meio de um horizonte próprio de compreensão. 
O diálogo do filósofo com a psicanálise tem sido alvo de numerosos estudos, particularmente no que diz respeito a sua leitura e compreensão da noção de inconsciente. Antes de nos determos propriamente nesse ponto, cabe situar brevemente essa discussão mais ampla de seu pensamento com a reflexão psicanalítica, o que aqui faremos por meio da delimitação do campo de investigação próprio a cada um deles. Nesse sentido, é possível reconhecer certa divergência de princípio, formulada de maneira contundente por um dos principais expoentes da psicanálise. Em seu seminário XI, Lacan (2008) nos adverte sobre uma diferença de "norte" que afastaria irremediavelmente a proposta da psicanálise daquela formulada pela fenomenologia de Merleau-Ponty, mesmo em seus desdobramentos finais, reconhecendo entre elas uma distinção de base: se cabe à psicanálise propor uma compreensão da "esquize" do sujeito (LACAN, 2008, 76), circunscrevendo-o em sua fratura originária, concentrando-se no "corte" (LACAN, 2008, p. 48) e na falta em torno dos quais a subjetividade gravita perpetuamente, à fenomenologia merleau-pontyana cabe o reconhecimento de uma distância de si graças ao reconhecimento da pré-constituição do mundo, instituição originária que necessariamente des-identifica o sujeito:

Mas não é entre o visível e o invisível que, nós outros, temos que passar. A esquize que nos interessa não é a distância que se prende ao fato de haver formas impostas pelo mundo e para as quais a intencionalidade da experiência fenomenológica nos dirige, donde os limites que encontramos na experiência do visível. O olhar só se nos apresenta na forma de uma estranha contingência, simbólica do que encontramos no horizonte e como ponto de chegada de nossa experiência, isto é, a falta constitutiva da angústia da castração (LACAN, 2008, p. 76).

Delimitando com clareza a distância que separa o projeto da psicanálise daquele defendido pela fenomenologia de Merleau-Ponty, Lacan reconhece que enquanto esta se volta à distância sensível que afasta o sujeito de si mesmo, aquela se ocupa da falta intrínseca e constitutiva advinda da castração. Mais ainda, ele circunscreve com precisão a distância entre o "lugar" em que se situa, para cada uma delas, essa espécie de "ruptura" ou de afastamento do sujeito. Segundo ele, em Merleau-Ponty, a esquize subjetiva seria buscada na distância instaurada pela espessura do mundo, pela ecceidade do percebido, irredutível às estruturas da subjetividade e assegurada pela presença irrecusável - as “formas" - do mundo. Na psicanálise, ao contrário, ela figuraria precisamente no corte, na falta e na angústia que lhe seriam próprias. Assim, se o filósofo avança para além dos limites de sua própria fenomenologia, não é para encontrar aí o mesmo objeto que a psicanálise, mas para explicitar essa distância advinda da espessura de um mundo que atravessa o sujeito, no qual ele ao mesmo tempo se afasta e se aproxima de si, vidente visível. É essa reversibilidade ou esse quiasma da experiência, cuja tessitura ou integridade parece afastá-lo da "fratura" em torno da qual a psicanálise deve gravitar, o núcleo ao qual sua fenomenologia se dirigiria, distanciando-a, por isso mesmo, do projeto psicanalítico.

É justamente essa indicação que procuraremos tematizar aqui, concentrando-nos nessa espécie de ausência de ruptura apontada por Lacan nas concepções do filósofo. Desdobrando essa proposição, procuraremos destacar um de seus aspectos que, como veremos, parece ter sido pouco considerado por outras leituras de sua obra advindas da psicanálise. Embora saibamos que a crítica de Lacan é desdobrada e desenvolvida em outros momentos ${ }^{1}$, o que nos interessa aqui é essa observação de que, mesmo distinta daquela formulada pela psicanálise, há na reflexão do filósofo o reconhecimento de uma esquize do sujeito, cujo "espaço" deve situar-se sobretudo na distância de si instaurada pelas relações intencionais - e originárias - que o atam irremediavelmente ao mundo, imbricação entre o visível e o vidente. Lacan não afirma, pois, a identidade do sujeito merleau-pontyano nem uma positividade de suas descrições. Ao contrário, sua formulação nos permite depreender o reconhecimento da presença de certa negatividade nas descrições do filósofo, ainda que seu sentido e seu lugar sejam distintos daqueles da psicanálise. Será justamente esse ponto que desenvolveremos nesse artigo: a explicitação de uma negatividade que, se não se alinha à fratura psicanalítica, nem por isso se deixa reduzir a uma forma qualquer de positividade. 
É esse reconhecimento, de algum modo apontado por Lacan, que parece, por sua vez, ter sido abandonado pelas leituras que outros psicanalistas fizeram do pensamento de Merleau-Ponty, como nos mostra Ayouch (2012) em sua retomada daquilo que ele próprio considera uma tradição interpretativa advinda da psicanálise a respeito do pensamento do filósofo.

Retomando a discussão sobre os limites entre a psicanálise e a fenomenologia merleau-pontyana, o autor enumera três aspectos que, segundo ele, as afastariam por princípio: o primeiro diria respeito à atestação: enquanto a fenomenologia é descritiva, a psicanálise é construtiva; o segundo refere-se à "incongruência de seus quadros epistemológicos", concernente sobretudo à reprovação que diversos autores fenomenólogos endereçaram a múltiplas dimensões da teoria freudiana; e o terceiro enfatiza a importância da clínica na construção psicanalítica, dimensão ausente da abordagem fenomenológica (AYOUCH, 2012, p. 175-177).

Compreendidas a partir desses referenciais, a fenomenologia seria a descrição da dimensão expressiva e significativa inscrita na percepção, ao passo que a psicanálise seria uma construção prática (clínica) de uma significação destinada a gravitar em torno de um núcleo não significativo, o inconsciente. ${ }^{2}$ Retomando a matriz lacaniana, a psicanálise deve orbitar ao redor de um sujeito "fraturado", cindido, distanciando-se de uma compreensão fenomenológica segundo a qual o percebido seria, por si mesmo, pregnante do significado, e o sujeito, em conformidade com ele, uma espécie de articulação expressiva entre o corpo e a significação. É aqui, mostra Ayouch, que concordam as principais leituras endereçadas pela psicanálise a Merleau-Ponty. Segundo ele, Pontalis (1993) sugere que uma teoria da percepção, centrada no corpo, não teria como apropriar-se da teoria freudiana sem desnaturá-la; Green (1973), por sua vez, aponta que enquanto Merleau-Ponty privilegia a percepção, a psicanálise privilegiaria a estrutura, sobrepondo a significância ao sentido percebido; já Castoriadis (1997) reprova também o privilégio dado à percepção, já que isso faria perder de vista o caráter criativo da psique e a dimensão simbólica da experiência (AYOUCH, 2012, p. 179, 180).

Assim, seguindo esse eixo proposto por Ayouch, podemos reconhecer que todos os autores convocados por ele teriam de algum modo reencontrado uma espécie de "positividade" na noção de inconsciente proposta pelo filósofo, por demais vinculada ao sensível e ao corpo, presa a uma teoria de percepção quase naturalista e desprovida de qualquer dimensão estrutural. Afirmando a continuidade entre o gesto expressivo e a significação, entre o sensível e o sentido, o filósofo não teria sido capaz de formular efetivamente a "ruptura" entre o consciente e o inconsciente, entre a significação e sua ausência. ${ }^{3}$ Se o sensível nos dá o sentido, se o corpo é o quiasma que nos une a ele, fazendo com que o sentido transborde na consciência e, para além dela, em sua invisibilidade, ${ }^{4} \mathrm{o}$ que se pode depreender desse movimento é a permanência e a "continuidade" entre todas as suas etapas, todas elas dependentes da relação primária inaugurada pelo corpo e pelo sensível, determinante, enfim, do próprio inconsciente e de seu modo de funcionamento.

A noção de inconsciente proposta pelo filósofo, assim compreendida, se veria então elidida pela primazia do sensível e por sua subordinação frente à percepção e à corporeidade. Subordinação que se encontraria cristalizada - e nos concentraremos, mais adiante, nesse ponto - na divergência entre uma teoria centrada na significação e outra centrada no inconsciente ou, nos termos postos por Ayouch, entre a fenomenologia como descrição da expressão e a psicanálise como estudo sobre a estrutura (AYOUCH, 2012, p. 180). Vinculado ao corpo, o inconsciente apenas poderia ser pensado a partir do modelo expressivo proposto pelo filósofo e, chega a afirmar Ayouch, até mesmo apenas na esteira da gestualidade corporal. Faltaria a ele, então, o estatuto propriamente estrutural que permitiria circunscrever seu caráter diferencial e diacrítico (AYOUCH, 2012), assegurando a dimensão de negatividade necessária ao inconsciente. O equívoco fundamental do filósofo estaria, enfim, em uma compreensão positiva do inconsciente, subordinado a um corpo e a um sensível sólidos, plenos, distantes de qualquer funcionamento estrutural: 
A fonte dessa oposição é o divórcio entre a concepção psicanalítica do sentido inscrito na estrutura, e a concepção fenomenológica do sentido imediatamente oriundo da percepção. Estas duas concepções se fundamentam numa perspectiva diferente sobre o corpo. (...) Os paradigmas do sentido são, de fato, diferentes entre a fenomenologia e a psicanálise. (...) há uma grande diferença entre o modelo da expressão por um lado - onde o sentido jaz na fusão do exprimido e da expressão - e o modelo estrutural por outro lado - onde o sentido é diacrítico, e se forma por um processo de diferenciação e oposição interna aos elementos (...) O modelo fenomenológico de sentido desenvolvido por Merleau-Ponty é o modelo da expressão, diretamente inscrita no corpo (AYOUCH, 2012, p. $180)$.

O que articularia, enfim, as críticas ao filósofo seria o reconhecimento da falta de uma dimensão propriamente estrutural em suas descrições. Merleau-Ponty não teria sido capaz de pensar uma lógica própria ao inconsciente, e seu modelo de expressão, advindo de sua noção de corpo e de sensível, acabaria por repor uma "positividade" que um recurso detido à noção de estrutura, tal qual empreendido por Lacan, poderia ter evitado. Desse modo, mais do que propriamente uma discussão sobre o estatuto do inconsciente, o que parece de fato estar em questão nessas críticas é certa compreensão sobre a estrutura ou a ausência dela - em suas descrições e, consequentemente, sobre o estatuto da percepção e do corpo. ${ }^{5}$

Feita essa breve circunscrição, seriam muitos os pontos que aqui poderíamos delimitar para nossa discussão. Nesse artigo, o que procuraremos tematizar, em consonância com nossa proposta de explicitar a importância do diálogo de Merleau-Ponty com Freud já no início de sua reflexão, ${ }^{6}$ é precisamente essa afirmação da ausência de uma dimensão estrutural nas proposições do filósofo e, através dela, o estatuto da percepção, dois elementos fundamentais, como veremos, para a compreensão de sua descrição do inconsciente. ${ }^{7}$ Buscaremos mostrar que essa suposição de uma "continuidade" entre o sensível e a consciência acaba por perder de vista o caráter fundamental da estrutura perceptiva descrita por Merleau-Ponty: sua dimensão de abertura e de diacriticidade, sem a qual sua noção de inconsciente torna-se, de fato, quase ingênua. Ignorando a existência de uma dimensão estrutural e de uma negatividade próprias à percepção, fazendo da consciência o desdobramento de um corpo e de um sensível plenos e puros, o inconsciente descrito pelo filósofo não poderia recair senão em uma forma qualquer de positividade.

O que procuraremos sustentar, ao contrário, é que, mais do que essa suposta "continuidade" entre a consciência e o inconsciente, o que de fato está em questão em suas descrições é uma revisão do próprio estatuto da consciência e de sua articulação com a percepção, de modo a fazer com que a "abertura" e a equivocidade (marcas, para o filósofo, do inconsciente) passem a ser compreendidas como estruturais dela: o inconsciente, como veremos, não será o outro da consciência, não haverá entre eles uma "fratura" - e, nesse sentido, retomamos a delimitação proposta por Lacan -, mas isso não significará - e aqui divergimos da perspectiva apontada por Ayouch - fazer do inconsciente uma "continuação" da consciência, seu desdobramento positivo.

Assim, não se trata de negar a relação entre percepção e consciência e, de ambas, com o inconsciente, mas de reconhecer em todas essas dimensões o seu caráter estrutural e negativo, sua abertura originária. ${ }^{8} \mathrm{Na}$ mesma medida, não se trata de afirmar, como bem descrito por Lacan, um "corte" no interior da fenomenologia de Merleau-Ponty. Ao contrário, o que procuraremos explicitar e circunscrever aqui é justamente a presença de uma negatividade que não é nem a da "fratura" psicanalítica nem a da "continuidade" do positivismo. Nem ruptura e nem plenitude, ela é algo que aqui delimitaremos como "abertura" ou "equivocidade" - "tremor", para recorrer a um termo usado pelo filósofo em um comentário sobre Heidegger.

Examinemos, pois, as noções de estrutura, percepção e consciência no início da reflexão do autor, sobretudo em A estrutura do comportamento e a Fenomenologia da percepção, depreendendo daí como a noção de inconsciente e o diálogo com Freud vão sendo paulatinamente construídos, mais importantes e 
coesos do que se costuma supor, já aí gravitando em torno de uma compreensão própria sobre a estrutura e a negatividade.

Em A estrutura do comportamento, Merleau-Ponty procura propor a compreensão do comportamento como estrutura, ${ }^{9}$ configuração dinâmica aquém da dualidade entre "sentido" e "matéria", nem ideia nem objeto puros. Como veremos, será principalmente essa noção que lhe permitirá "revisitar" aí o estatuto da consciência, reconhecendo nela uma dinâmica que não pode mais admitir a cisão entre um campo consciente e outro inconsciente, aproximando-se, ao contrário, da configuração perceptiva e de seu funcionamento simultaneamente unitário e diacrítico.

Compreendida em sua dinâmica própria, a estrutura é uma unidade ao mesmo tempo significativa e concreta, que não pode deixar intacta a suposição do sujeito como instância constituinte que operaria sobre uma matéria inerte. Ao contrário do que supõem as teorias da época - tanto em sua vertente empirista quanto intelectualista -, trata-se para o filósofo de explicitar a estrutura como uma totalidade formada espontaneamente pela organização de suas partes, articulação cuja existência prescinde de todo ato intelectual deliberado e de toda composição objetiva das excitações e das reações, alojando-se na relação intrínseca que vincula a parte e o todo sem necessidade de um operador externo.

O estímulo físico não provoca uma reação específica, não desperta uma série de mecanismos preestabelecidos; do mesmo modo, a consciência não designa uma operação espiritual que nada deveria ao seu corpo e a sua situação. Ao contrário, o comportamento opera em relação orgânica com seu campo, configurando-se como uma resposta global, aberta e qualitativamente variável, conforme o contexto e o sentido em questão. Mais do que causa, a situação é ocasião para uma resposta. Entre o sujeito e seu "meio", não se pode mais delimitar quem age e quem padece, fazer de um a causa - seja empírica, alojada no estímulo, ou transcendental, alojada na consciência - e do outro efeito, pois o que os une é a relação de sentido que estabelecem entre si, articulação interna: o estímulo é incorporado à significação própria ao organismo, e a reação traz o estímulo como uma de suas possibilidades intrínsecas.

A ação do mundo sobre o indivíduo não pode então ser pensada como uma operação externa que o tornaria passivo, pois ela se dá segundo uma organização que é intrínseca ao organismo. Mas também não pode ser pensada como um reflexo da atividade desse indivíduo, pois há uma significação própria ao estímulo e a sua configuração. Momentos de uma estrutura comum, do mesmo núcleo significativo, as dimensões passiva e ativa do comportamento se fundem. Afirma-se simultaneamente que o comportamento tem um sentido e que este permanece dependente do valor vital da situação. Impossível, portanto, defini-lo como coisa em si, que existiria partes extra partes, ou como puro para si, idealidade abstrata, sendo preciso reconhecê-lo como "dialética encarnada" (MERLEAU-PONTY, 1967, p.174), unidade que irradia sua estrutura sobre o ambiente, formando com ele um todo de influência recíproca.

Vem do reconhecimento desse elo intrínseco entre o organismo e seu meio a necessidade de uma revisão do estatuto da consciência, explicitando seu caráter situacional e, sobretudo, estrutural, o que será feito pelo filósofo, já aqui, por meio da descrição de seu vínculo originário com a percepção. ${ }^{10}$ Inscrita nessa "dialética" primária, ela não será posicional, como supõe tanto o objetivismo quanto o intelectualismo, mas estrutural, preservando os dois momentos em torno da configuração comum que os incorpora e lhes dá forma. Como fará ao longo de toda a sua obra, Merleau-Ponty busca afastar-se, já em A estrutura do comportamento, da compreensão da percepção a partir das concepções dualistas erguidas pela tradição. De modo geral, mostra ele, ao pensar a relação entre a consciência e a percepção, a psicologia e a filosofia tendem a supor uma noção de consciência inteiramente atual para dar conta da especificidade do ato perceptivo, sua capacidade de apreender existências individuais (MERLEAU-PONTY, 1967, p.177). Quer seja concebida, como em Bergson, como uma duração continuada (MERLEAU-PONTY, 1967, p. 176), 
ou, como em Brunschvicg (MERLEAU-PONTY, 1967, p. 177), como uma fonte de julgamentos, a consciência permanece uma atividade pura, sem natureza e sem estrutura, desprovida de relações internas com aquilo que não é ela mesma. Como consequência, a percepção, tomada naquilo que tem de próprio - isto é, "enquanto conhecimento e modificação de uma realidade" (MERLEAU-PONTY, 1967, p. 177) -, é rejeitada da esfera da consciência. Admite-se que ela tem por função enraizá-la no Ser (MERLEAU-PONTY, 1967, p. 177), mas ela permanece sem conteúdo, respondendo a uma necessidade abstrata. Preserva-se a dissociação entre o que existe e o fato de sua existência, entre a consciência de conteúdos e a consciência da ação que os vincula ao Ser. A consciência pode assim permanecer definida como posse de um objeto de pensamento, transparência de si a si; e a ação como uma série de eventos exteriores uns aos outros. De um lado, uma força causal, de outro, um mosaico de sensações que ela transformaria.

É justamente esse dualismo que a percepção põe em questão: "Em realidade, é justamente essa distinção da estrutura e dos conteúdos, da origem psicológica e da origem transcendental, que está em questão" (MERLEAU-PONTY, 1967, p. 180, 181). Compreendida em termos de estrutura, o que a percepção testemunha é precisamente uma unidade primária que torna impossível a ruptura entre intelecção e existência concreta. Na percepção efetiva, não há de um lado um ato de consciência e, de outro, uma série de sensações exteriores umas às outras e sem qualquer significação própria. O que há são unidades concretas, conjuntos significativos que se fazem pela articulação de seus elementos, deixando-se apreender de modo indiviso como polos de ação e núcleos de conhecimento (MERLEAU-PONTY, 1967, p. 179). Enquanto "momento da dialética viva de um sujeito concreto" (MERLEAU-PONTY, 1967, p. 179), a dinâmica perceptiva não permite isolar os atos de seu conteúdo, a consciência dos termos nos quais se lança. Por um lado, ela tende a visar intenções humanas, mais do que qualidades puras; e por outro, ela os conhece como realidades e não como objetos (MERLEAU-PONTY, 1967, p. 180): ou seja, a percepção não reconhece a separação entre qualidades objetivas e atos subjetivos, entre o domínio da existência e o da significação.

Motivo pelo qual, segundo Merleau-Ponty, mesmo a compreensão kantiana sobre a atividade da consciência permanece insuficiente, pois a distinção entre estrutura a priori e conteúdos a posteriori mantém implícita ainda uma relação de contiguidade entre a matéria e o sentido: "Como a distinção do conteúdo sensível e da estrutura a priori é uma distinção segunda (...) impossível na consciência infantil - pois existem os "a priori materiais", a ideia que devemos fazer da consciência é profundamente modificada" (MERLEAU-PONTY, 1967, p. 186).

O "a priori material" - noção advinda de Husserl - é referido aqui por Merleau-Ponty justamente como articulação intrínseca entre sentido e matéria, unidade e multiplicidade, configurando o tipo de estrutura ao qual a percepção tem acesso. Ao contrário do ato intelectual, $\mathrm{o}$ ato perceptivo testemunha que o sentido é dado antes das supostas qualidades sensíveis - anterior à separação das partes -, presente no próprio percebido, em sua organização concreta. Ao perceber um rosto, por exemplo, reconheço a fisionomia mesmo que não saiba discriminar seus detalhes. Um olhar me aparece não como uma entidade físico-química, mas como um centro de expressão humana, lugar de aparição de uma multidão de intenções (MERLEAU-PONTY, 1967, p. 182); nem matéria inerte nem significação abstrata. Em uma palavra, o que a percepção apreende não é o sentido ou a existência, mas a estrutura que os une (MERLEAU-PONTY, 1967, p. 182) - uma matéria já significativa, sentido existencial anterior à distinção entre o intelectual e o empírico.

Razão pela qual o modo de existência do percebido não é o da ideia clara e distinta ou o do objeto estático. Ele não aparece como algo externo ao ato perceptivo, mas como solicitação, conjunto de linhas de força que demanda um tipo de ação, termo imanente de uma atividade prática, conforme a unidade significativa que forma com o organismo. Ele não atua como uma determinação externa à consciência (seja ela social ou psicológica), mas como expressão de sua "forma original", revelando-a inscrita na fusão 
originária que une sentido e existência. Inserida nesse conjunto, a consciência se descobre não como posição de um objeto que a representaria, mas como abertura a uma realidade que a demanda e constitui, abandonando a posição de fonte autônoma geradora de significações: "Nos propomos a mostrar que o aspecto descritivo da percepção 'começante' exige uma reforma da noção de consciência" (MERLEAU-PONTY, 1967, p. 183).

A percepção conduz a uma outra noção de consciência porque revela essa significação que se mantém inseparável de seus elementos concretos, formando-se como unidade espontânea que recorre ao múltiplo para realizar-se, organizada pela lógica intrínseca de suas partes. Reconhecida em sua forma originária, a estrutura perceptiva impede conceber a consciência como função universal de organização da experiência, que imporia a todos os objetos as condições da existência lógica, operante sobre uma materialidade inerte desprovida de significação. O que a análise da percepção ensina é precisamente a dimensão espontânea de todo sentido, seu "brotamento imotivado", movimento intrínseco pelo qual uma multiplicidade $s e$ articula em torno de uma significação comum, sem a necessidade de um ato intelectual externo, unidade concreta e significativa:

\footnotetext{
Além da oposição fática entre o inato e o adquirido, trata-se então de descrever, no momento mesmo da experiência, quer ela seja precoce ou tardia, interna ou externa, motora ou sensorial, a emergência de uma significação indecomponível. É preciso que a língua entendida ou esboçada, a aparência de um rosto ou aquela de um objeto de uso, sejam imediatamente para a criança invólucros sonoros, motores ou visuais de uma intenção significativa vinda de outrem (MERLEAU-PONTY, 1967, p. 185).
}

Assim compreendida, sentido prático e operante, a estrutura antecede a cisão entre a consciência e a realidade, explicitando a abertura originária que as une. Ela não é o objeto correlato a uma subjetividade pura, mas a configuração que se oferece a uma consciência capaz de abrir-se ao que não é ela, ao sentido concreto que lhe aparece e do qual participa. O que se revela na percepção não é um dado objetivo, mas a estrutura em sua organização complexa, isto é, enquanto indistinção do passivo e do ativo, reciprocidade aquém da distinção clássica entre sujeito e objeto (MERLEAU-PONTY, 1967, p. 185).

Desse modo, mesmo envolvendo um centro cognitivo, a relação que o ato estabelece com seu termo, sua referência ao seu "objeto" - do desejo ao desejado; da vontade ao intencionado; do medo ao temido (MERLEAU-PONTY, 1967, p. 187) -, não pode ser reduzida ao vínculo posicional do representante e do representado, mantida sob o modelo dualista clássico. Ao contrário, ela encontra-se agora inscrita na unidade primária configurada pela estrutura, em que um termo não pode ser afirmado sem o seu outro: entre eles há uma união interna originária, "reconhecimento vago" (MERLEAU-PONTY, 1967, p. 187) e não tético que prescinde de qualquer mediação externa. A consciência, assim como o desejo e a vontade, estabelece com o "objeto" uma relação estrutural, totalidade feita por implicação e constituição recíprocas, impossível para uma visão objetiva. Retomando o caráter referencial dos elementos, cabe reconhecer que a consciência opera sob a inter-relação primária existente entre o sujeito e o real.

O "reconhecimento vago" que os reúne se apoia sobre o caráter dialético de sua relação, referência interna de um ao outro. E é justamente a partir dele que Merleau-Ponty começa a propor seu diálogo com Freud - em um primeiro momento, em uma perspectiva de distanciamento -, pois essa espécie de "imprecisão" da consciência não pode significar, para o filósofo, nenhuma forma de inconsciente separado, e seu recurso à percepção não pode ser confundido com a afirmação de uma dimensão "não consciente" na consciência, suposição de um fundo obscuro ou opaco que escaparia à intelecção - vinculando o percebido a uma dimensão inconsciente que reporia a separação entre a consciência e a realidade. Ao contrário, o reconhecimento espontâneo da consciência reflete precisamente a irredutibilidade de seu vínculo com algo que não ela própria, nem objeto nem latência, mas referência para além de si, imbricação originária 
com o termo visado, com o outro. ${ }^{11} \mathrm{O}$ que ele reflete não é a dimensão inconsciente dos atos conscientes, mas a abertura inscrita em todo ação, sua dinâmica estrutural - tanto no plano perceptivo quanto cognitivo.

A redução do sentido percebido ao "conteúdo latente" ou "inconsciente" equivaleria a postular que a consciência não pode ter acesso a nada que não lhe estivesse presente como representação ou conteúdo. É exatamente o contrário o que a percepção ensina, mostrando essa referência e essa "presença vaga" que não são da ordem da constituição, que não dependem de atos posicionais e não se reduzem a produto de uma atividade deliberada:

\begin{abstract}
O que nós dissemos basta para fazer ver que a posse de uma representação ou o exercício do julgamento não é coextensivo à vida da consciência. A consciência é mais uma rede de intenções significativas, às vezes claras para si, às vezes, ao contrário, vividas mais do que conhecidas. Uma tal concepção permitirá religá-la à ação ao alargar nossa ideia de ação (MERLEAU-PONTY, 1967, p. 187).
\end{abstract}

Se a consciência se define por sua referência a um termo distinto de si, e não mais pela posse de uma representação, ela não pode ser concebida por referência a qualquer conteúdo inconsciente alojado em seu interior, mas sim por sua abertura primária, relação estrutural com a alteridade. Vem daí o distanciamento que Merleau-Ponty procura estabelecer inicialmente com relação a Freud, por reconhecer nele a permanência de uma noção de inconsciente acentuadamente objetiva e causal. Como veremos, essa leitura, mesmo em A estrutura do comportamento, já é relativizada pela possibilidade de um outro viés interpretativo - aquele que será paulatinamente defendido por Merleau-Ponty -, mas ela estabelece um eixo que o filósofo manterá ao longo de toda a sua reflexão: o reconhecimento da possibilidade de diversas interpretações sobre o inconsciente, mesmo em Freud, ${ }^{12} \mathrm{e}$ a recusa de todas aquelas que tendem a uma explicação de cunho objetivista e cientificista.

Assim, a questão que o filósofo se coloca aqui é saber se os conflitos, os mecanismos psicológicos, descritos por Freud, realmente exigem o sistema de noções causais pelo qual ele majoritariamente os interpreta (MERLEAU-PONTY, 1967, p. 192). O desenvolvimento humano, por exemplo, ao invés de concebido em termos de causalidade, poderia ser pensado como uma estruturação progressiva e descontínua do comportamento (MERLEAU-PONTY, 1967, p. 192). A estruturação normal seria aquela que o reorganiza em profundidade, em que as atitudes infantis não têm mais espaço, dando lugar a um comportamento efetivamente integrado, onde cada momento se articula ao conjunto. Ao contrário, haveria um "trauma" quando a integração não se realiza de modo pleno, subsistindo certos sistemas relativamente isolados que o sujeito recusa transformar e assumir. Um complexo seria um segmento de comportamento desse gênero, atitude estereotipada em uma forma determinada de consciência, permanente e adquirida, tornada recorrente diante de um tipo específico de estímulo.

Assim interpretado, ele não seria um dado "objetivo" inconsciente, mas justamente uma estrutura da consciência. Um acontecimento que não pode ser elaborado e que por isso vem acompanhado de angústia e desordem (MERLEAU-PONTY, 1967, p. 192), inapreensível diretamente, mas que se faz sentir pela fisionomia constante que assume a partir da situação traumática. Daí por diante, cada situação "nova" se estrutura segundo essa forma fixa, mantendo-se sempre o mesmo resultado. Como o membro fantasma e a afonia de que falará a Fenomenologia da percepção ${ }^{13}$ (MERELEAU-PONTY, 1994), o trauma concerne à estrutura e não ao conteúdo do comportamento, ele é forma e não objeto.

"O complexo não é então como uma coisa que subsistiria no fundo de nós para produzir de tempos em tempos seus efeitos na superfície. Ele não está presente fora dos momentos” (MERLEAU-PONTY, 1967, p. 192). 
Não estando aquém do comportamento efetivo, o complexo se faz nele, estrutura-o, lhe dá forma e sentido. É o que permite a Merleau-Ponty afirmar que não existe propriamente inconsciente, no sentido de algo que existiria fora de sua manifestação (MERLEAU-PONTY, 1967, p. 192), independente de toda dinâmica expressiva. ${ }^{14} \mathrm{Se}$ o complexo se torna a própria estrutura do comportamento considerado, necessariamente ele se faz legível nela, encontrando aí um modo de expressão, ainda que não explícito. Existindo na configuração concreta do conjunto, o complexo não pode ser uma zona opaca que operaria por sob a consciência, aquém de toda forma de aparição.

Para o analista, por exemplo, ele não é uma região autônoma ou obscura, mas o próprio meio de acesso e de compreensão da montagem presente e geral em que se inscreve. Uma consciência tornada infantil, no caso do sonho, ou tornada dissociada, no caso do complexo (MERLEAU-PONTY, 1967, p. 193). Sem poder ser isolado do comportamento total, o inconsciente não é "causa" determinada das condutas do sujeito - no sentido de que não há fragmentos isoláveis que pudessem atuar sem vínculo com a totalidade. O comportamento não admite nenhuma particularidade sem incorporá-la a sua conduta geral, ao mesmo tempo que não admite nenhuma generalidade sem expressá-la por meio de suas partes. Inserido nessa dinâmica, o complexo não "produz" o comportamento, e não se ausenta dele sob a forma de um inconsciente separado.

Assim, aos olhos de Merleau-Ponty, o que as descobertas de Freud exigem é essa possibilidade de uma “(...) vida da consciência fragmentada que não possui em todos os seus momentos uma significação única” (MERLEAU-PONTY, 1967, p. 193), isto é, elas exigem a presença do particular e do caráter diferencial no interior da totalidade, reconhecimento da não identidade da consciência. Mas isso não o obriga a negar sua unidade, transformando-a em uma soma de regiões autônomas ou mesmo inconscientes. Ao contrário, segundo o filósofo, a aparente "inconsciência" testemunhada por Freud relaciona-se justamente ao caráter estrutural da consciência (MERLEAU-PONTY, 1967, p. 193), à equivocidade intrínseca a uma unidade internamente diferenciada. $\mathrm{O}$ trauma não pode ser, portanto, a manifestação de um conteúdo separado e autônomo, mas sim o retorno a uma maneira mais primitiva de organizar o comportamento, a um momento menos complexo e menos integrado da estrutura.

Ele confirma, assim, a capacidade da estrutura de diferenciar-se constantemente sem perda de sua unidade: não há ruptura na consciência porque ela opera segundo a dinâmica referencial que une internamente o particular e o geral. Longe do dualismo, ele confirma o caráter híbrido de sua configuração. Delineando mais claramente a perspectiva de apropriação merleau-pontyana que estamos procurando aqui circunscrever, é em direção a uma compreensão alargada da consciência que as descobertas de Freud apontariam e não no sentido de sua dualização: o que ele denomina como inconsciente seria, de fato, não o "outro" da consciência, mas sua dimensão de abertura e de dissonância. Como também as descrições seguintes nos ajudarão a explicitar, é nessa direção que Merleau-Ponty recorre a ele, justamente como explicitação de uma compreensão não objetivante e não dualista, apta a explicitar os limites inerentes a toda concepção dicotômica - é nesse sentido, que, mesmo compreendendo o sentido da afirmação dentro de sua argumentação mais ampla, divergimos da posição de Rodrigo (2002), quando afirma que a descrição de Freud receberia apenas um tratamento externo em $A$ estrutura do comportamento, figurando ali apenas como uma espécie de "exemplo" (RODRIGO, 2002, p. 32-34). Ao contrário, como estamos procurando mostrar, já ali o recurso e a discussão com o autor são incorporados organicamente por Merleau-Ponty às suas próprias proposições.

É essa mesma "labilidade" ou "abertura" intrínseca à consciência que podemos encontrar em A dúvida de Cézanne (MERLEAU-PONTY, 1975). Ali, Merleau-Ponty retoma uma temática fundamental ao longo de toda a sua reflexão: o aspecto situacional da liberdade, o caráter ao mesmo tempo livre e engajado da condição humana, explicitando, uma vez mais, um funcionamento diacrítico e aberto que não pode ser 
explicado por meio da cisão entre o consciente e o inconsciente, o manifesto e o latente. Retomando os eixos do pensamento da tradição, há, segundo ele, duas perspectivas vigentes que poderiam ser mobilizadas na tentativa de compreensão da liberdade presente na descrição de Cézanne.

Por um lado, uma leitura empirista ou determinista, aqui figurada no exemplo de Zola, que faria da obra a "manifestação" de sua personalidade ou de seus condicionamentos - no caso específico do pintor, uma decorrência de sua esquizoidia e de seus distúrbios (visuais e de comportamento). Transformando a obra em resultado de uma causalidade extrínseca, a criação é aqui anulada, fazendo da "liberdade" uma mera abstração. Os atos não são senão decorrência de algo que eles próprios não decidem, sempre aquém de qualquer dimensão subjetiva ou singular. A ideia de obra desaparece então, e seria preciso afirmar que a pintura de Cézanne - como a ação de todo sujeito - não é a resposta livre que seu "projeto" ou seu modo singular de existir configura (MERLEAU-PONTY, 1975), mas o resultado mecânico de uma causalidade objetiva, inteiramente determinável. Assim como ocorria nas explicações de cunho empirista tratadas antes, a consciência aqui se reduz a uma soma de processos mecânicos, não mais do que uma lógica objetiva que recusa qualquer dimensão de "plasticidade" e de transformação no comportamento.

Em direção aparentemente contrária, mas chegando a resultados próximos, a outra vertente tradicionalmente mobilizada para auxiliar na compreensão do fenômeno da liberdade encontra sua figuração no exemplo de Valéry, ${ }^{15}$ trazido ao ensaio por meio de sua discussão sobre Leonardo. Trata-se, mostra Merleau-Ponty, do aparente avesso do empirismo, proposição da figura do sujeito não mais como ausência de liberdade, mas justamente como "liberdade total", um "monstro de liberdade" como descreverá Valéry. Leonardo aparece, então, como uma espécie de consciência pura, desengajada e descompromissada, que nada deveria ao seu entorno, seu contexto ou seu passado. Sua obra figuraria como o resultado de uma escolha ou de um projeto inteiramente incondicionado, assumido sem qualquer tipo de motivação que não aquela proposta por si mesmo. Toda ação seria, assim, o fruto de uma decisão tomada por um sujeito "sem amarras no ser", uma subjetividade, como descreverá a Fenomenologia da percepção, inteiramente vazia e apartada do mundo, "pensamento de sobrevoo" sem corpo e sem tempo. Novamente, o que desaparece é a possibilidade de qualquer tipo de "tensão" ou de equivocidade na experiência. Se a consciência é inteiramente livre, se desconhece qualquer motivação que não provenha de si mesma, repõe-se aqui a figura erigida pelo pensamento moderno da consciência como pura coincidência, um Cogito que, por princípio, é pleno saber de si e que, por conseguinte, não pode ser qualquer coisa sem o saber. Subjetividade incapaz de admitir o equívoco, a contradição e a ambiguidade, ela está, por princípio, afastada de qualquer forma de inconsciência ou de ignorância de si.

Diante dessa alternativa entre empirismo e intelectualismo - figurada aqui na alternativa entre Zola e Valéry -, cujo resultado, na verdade, acaba por alcançar um denominador comum, uma consciência incapaz de abertura e de equivocidade, é que cabe o recuso de Merleau-Ponty a Freud. Retomando o estudo feito por ele também a respeito de Leonardo, ${ }^{16} \mathrm{o}$ filósofo o contrapõe ao de Valéry, justamente para explicitar como, em uma vida, “(...) sempre há elos, mesmo e sobretudo quando nos recusamos a admiti-los” (MERLEAU-PONTY, 1975, p. 313). Apoiando-se na análise freudiana sobre a "figura" do abutre para Leonardo, o filósofo busca explicitar a permanência de uma espécie de "enigma" ou de "fantasma" com o qual - aquém de suas decisões e escolhas deliberadas - $\mathrm{o}$ artista "tinha que se a ver". Nesse sentido, a solidão, o hábito de abandonar obras inacabadas, a frieza aparente que o caracterizavam, ao invés de testemunharem uma liberdade absoluta sem qualquer dimensão situacional, revelavam, ao contrário, as respostas configuradas por ele em relação àquilo que lhe "fora dado viver": "O nascimento e o passado definem para cada vida categorias ou dimensões fundamentais que não impõem nenhum ato em particular, mas que se leem ou se podem encontrar em todos" (MERLEAU-PONTY, 1975, p. 315). Nem abstração nem fatalidade, o passado e a história, a situação e o corpo, operam não como causalidade objetiva que determinaria 
a liberdade do sujeito nem como posição por ele próprio engendrada que nada diria a sua liberdade, mas como configuração de um campo aberto, estabelecimento de certas linhas de desdobramentos possíveis que, sem esgotar-se em nenhuma delas, reafirma-se em todas, explicitando uma subjetividade existencialmente aberta e diacrítica, incapaz de concentrar-se na forma da identidade ou da pura imanência. Tema central da obra de Merleau-Ponty, a liberdade reassume aqui seu caráter situacional e temporal, explicitando a tensão que a configura.

Do ponto de vista da discussão do filósofo sobre Freud, isso nos recoloca diante de uma questão próxima àquela que já podíamos reconhecer em $A$ estrutura do comportamento: o caráter híbrido ou "aberto" que seria necessário reconhecer na consciência. Como afirma Merleau-Ponty, o ponto "problemático" da psicanálise não estaria nas descobertas de Freud, mas, ao contrário, na tentativa de fazer delas uma ciência objetiva, operante segundo relações de causalidade, o que acabaria por contradizer a abertura e a dimensão de possibilidade inscritas na consciência que ela própria explicita - mesmo sem aperceber-se inteiramente disso:

O que pode haver de arbitrário nas explicações de Freud não autoriza desacreditar aqui a intuição psicanalítica (...) A psicanálise não é feita par dar-nos, como as ciências da natureza, relações necessárias de causa e efeito, mas para nos indicar relações de motivação que, por princípio, são simplesmente possíveis. Não concebamos o fantasma do abutre em Leonardo, com o passado infantil que recobre, como uma força que determinasse seu futuro. Trata-se, como o vaticínio do áugure, de um símbolo ambíguo que antecipadamente se aplica em várias linhas de acontecimentos possíveis (MERLEAU-PONTY, 1975, p. 315).

É enquanto possibilidade de reconhecimento do caráter aberto, relacional e "ambíguo", da consciência que a perspectiva freudiana, aos olhos de Merleau-Ponty, ganha força. Não como explicação exaustiva do comportamento, portanto, mas como explicitação de seu caráter, ao mesmo tempo, aberto e situado, reconhecimento de uma liberdade que não é nem absoluta nem vazia. É a "circularidade" da existência, sua dimensão polifônica, feita de retomadas e distensões, que a psicanálise ajuda a explicitar. Rede de implicações simbólicas, já aqui descrita, sobre a qual se deterão os cursos sobre a instituição (MERLEAU-PONTY, 2003).

Proposição semelhante, por sua vez, pode ser encontrada na Fenomenologia da percepção (MERLEAU-PONTY, 1994). As referências a Freud ali são diversas, bem como a discussão do filósofo com a psiquiatria e a psicologia da época. Aqui, conforme a linha que estamos perseguindo, nos concentraremos sobretudo em um ponto: a explicitação dessa relação não posicional e não designativa da consciência com seus objetos, por meio da qual Merleau-Ponty busca propor essa espécie de "releitura" do inconsciente freudiano. Para isso, recorreremos principalmente às descrições sobre o "lugar" ocupado pelas patologias e pela sexualidade em relação ao comportamento - e, por isso mesmo, também em relação à consciência -, momentos em que as referências a Freud são mais expíicitas, e que nos permitirão reencontrar a dinâmica estrutural explicitada anteriormente. ${ }^{17}$ Como veremos, o que se mantém em questão, uma vez mais, é a impossibilidade da compreensão da consciência dentro do modelo formulado pela tradição, reafirmando seu caráter de abertura e de equivocidade não como aquilo que a recusa, mas justamente como o que lhe dá configuração e sentido.

É isso que a referência de Merleau-Ponty aos casos patológicos nos ajuda a compreender. Não se trata, para o autor, do recurso a eles como o absolutamente outro diante de um suposto estado normal, mas de sua explicitação como variação ou reestruturação do comportamento, possibilidade por ele mesmo assegurada e dele ainda expressiva. ${ }^{18} \mathrm{~A}$ patologia não é aqui compreendida como negação da normalidade, mas como um horizonte de configuração inscrito na própria estrutura, precisamente enquanto totalidade 
aberta e diacrônica, ${ }^{19}$ capaz de alterar-se e reconfigurar-se sem perda de sua unidade, sem cisão ou duplicidade:

Se o histérico é um simulador, em primeiro lugar o é em relação a si mesmo, de forma que é impossível colocar em paralelo aquilo que ele verdadeiramente sente ou pensa e aquilo que ele exprime no exterior: o pitiatismo é uma doença do Cogito, é a consciência tornada ambivalente, e não uma recusa deliberada de confessar aquilo que se sabe (MERLEAU-PONTY, 1994, p. 223).

É contra a noção de uma consciência pura e inequívoca - e a decorrente necessidade de se supor um inconsciente separado para o que não se oferece a ela de modo inteiramente transparente - que as descrições patológicas feitas por Merleau-Ponty se colocam, e é novamente nessa direção que as descobertas da psicanálise são aqui valorizadas e incorporadas por ele. Assim, por exemplo, se ela mostra que todo esquecimento é um ato - na medida em que não se dá por acaso, supondo uma significação e a "recusa" de toda uma região vital (MERLEAU-PONTY, 1994, p. 224) -, ela ao mesmo tempo explicita que essa "relação intencional" com a recordação não equivale a uma posição explícita de seu "objeto", que o esquecido não se apresenta propriamente à consciência, já que então não haveria efetivamente esquecimento. $\mathrm{O}$ paciente que perde uma memória não se esquece de um conteúdo particular, não opera sobre um termo específico, mas é todo um campo de sua experiência que deixa de figurar, quase deixando de existir para ele. Esquecer não é um ato objetivo particular, mas uma reconfiguração existencial que se apoia no corpo e em sua generalidade:

\footnotetext{
Assim, na histeria e no recalque podemos ignorar algo ao mesmo tempo em que o sabemos, porque nossas recordações e nosso corpo, em lugar de se apresentarem a nós em atos de consciência singulares e determinados, dissimulam-se na generalidade. Através dela, nós as "temos" ainda, mas apenas o suficiente para mantê-las longe de nós (MERLEAU-PONTY, 1994, p. 224).
}

Tema central nas formulações de Merleau-Ponty, a noção de generalidade relaciona-se ao reconhecimento de uma passividade inerente a todo ato, à impossibilidade de uma cisão entre liberdade e situação. ${ }^{20}$ Para a discussão que aqui estamos buscando circunscrever, o importante é compreender que essa generalidade - que é tanto do corpo quanto da consciência - delimita um campo pré-objetivo, uma articulação originária e uma adesão geral à zona de nossa vida, sempre aquém da consciência pessoal ou posicional (MERLEAU-PONTY, 1994, p. 225). Assim, o sintoma não aparece ao paciente, nem mesmo ao analista, como um objeto diante de sua consciência ou como um efeito de estímulos objetivos: ele não é uma realidade objetiva. Ao contrário, como nos mostra também A estrutura do comportamento, ele opera sempre de modo generalizado, distendendo-se na configuração do comportamento. Apoiado na articulação intrínseca entre a parte e o todo própria à estrutura, o sintoma - mesmo que vinculado privilegiadamente a uma região específica - se dilata em formas mais gerais, "ganha corpo" interferindo na totalidade funcional do conjunto. ${ }^{21}$

É justamente essa dinâmica operante entre o conjunto e suas partes que nos permite compreender, também, o "lugar" da sexualidade em relação à existência. A Fenomenologia da percepção se ocupa de uma complexa descrição a fim de explicitar como a relação que se estabelece entre elas não pode ser reduzida nem à pura identificação nem à pura exterioridade (MERLEAU-PONTY, 1994). A sexualidade não é um ciclo autônomo, que nada diria à totalidade do comportamento, nem um "centro" ou um inconsciente, que o determinaria mecanicamente sem nada envolver ou expressar dele. Nem autônoma nem subordinada, ela reafirma a "rede de implicações" que já encontrávamos nas descrições anteriores. E é novamente a Freud que o filósofo recorre, uma vez mais como testemunho e auxílio para a compreensão dessa estrutura híbrida, agora não apenas se aproximando dele, mas, em termos mais gerais, aproximando-o do projeto mais amplo da fenomenologia. O mérito da psicanálise estaria, então, em "reintegrar a sexualidade 
no ser humano" (MERLEAU-PONTY, 1994), não enquanto transposição do psíquico no biológico, mas enquanto explicitação de uma "dialética" em funções que se suponham apenas corporais e de uma dimensão sexual em relações que se supunham apenas conscientes (MERLEAU-PONTY, 1994) - ou seja, enquanto explicitação da insuficiência do modelo dualista e de suas cisões:

Mesmo em Freud seria um erro acreditar que a psicanálise exclui a descrição dos motivos psicológicos e se opõe ao método fenomenológico: ao contrário, ela (sem o saber) contribui para desenvolvê-lo ao afirmar, segundo a expressão de Freud, que todo ato humano "tem um sentido", e ao procurar em todas as partes compreender o acontecimento, em lugar de relacioná-lo a condições mecânicas (MERLEAU-PONTY, 1975, p. 218).

Como já mostrava a Estrutura do comportamento, é na articulação entre a parte e o todo, na explicitação de uma significação intrínseca ao comportamento, que a psicanálise aproxima-se da fenomenologia, e, mais ainda, na explicitação do caráter não objetivo e não posicional dessa significação, distinta de qualquer termo positivo ou isolável e da correlata suposição de uma consciência inteiramente clara e translúcida. É ao pré-objetivo, nesse sentido, que ela nos remete, reencontrando o projeto mais amplo de Merleau-Ponty. Assim, mesmo em Freud, a sexualidade não se deixaria apreender segundo as alternativas do pensamento dualista: ela não é signo do comportamento, no sentido convencional, ${ }^{22}$ nem sua causa, ${ }^{23}$ mas uma estrutura que participa dele e que lhe dá tanto quanto recebe. Como todo elemento do comportamento, a sexualidade é integrada à configuração geral, com a qual mantém uma relação ao mesmo tempo de afirmação e de diferença, de particularização e de explicitação. É nesse sentido que ela, ao mesmo tempo, assume e distingue-se da existência: ela a assume, na medida em que a existência se expressa nela, aí se singulariza e se distende; ela se distingue, na medida em que nenhum campo ou dimensão da experiência, por mais largo e dilatado que seja, pode esgotar a existência, pode fazer frente a sua generalidade. Nem identificada nem apartada do comportamento, o caráter dialético da sexualidade descrita por Freud confirma a necessidade de uma alternativa ao pensamento dicotômico, reconduzindo-nos aquém da dualidade entre o mecânico e o pessoal, o inconsciente e o consciente:

Existem aqui dois erros a se evitar: um é não reconhecer à existência outro conteúdo que não seu conteúdo manifesto; o outro é duplicar esse conteúdo manifesto como um conteúdo latente, como o fazem as psicologias do inconsciente. A sexualidade não é nem transcendida na vida humana nem figurada em seu centro por representações inconscientes. Ela está constantemente presente ali, como uma atmosfera (MERLEAU-PONTY, 1996, p. 232).

Do mesmo modo que o inconsciente, a sexualidade não está propriamente dada em parte alguma, não é nem um fato nem uma ilusão: antes, trata-se de um campo ou de uma dimensão, forma privilegiada do comportamento que ora o confisca para si, ora se deixa levar por seu movimento mais amplo. Ela não é um elemento objetivo da existência, mas uma configuração funcional em permanente tensão com a totalidade da qual se diferencia e à qual retorna permanentemente. É a ideia de estrutura, portanto, que nos permite compreender o papel da sexualidade na condição humana, explicitando, uma vez mais, a articulação dinâmica existente entre o conjunto e suas "partes": o papel da sexualidade é sistêmico e sua configuração se inscreve na articulação que reúne os "setores" em uma unidade operante. Assim como o inconsciente não é o "outro" da consciência - sua negação ou sua ausência -, mas uma forma dela - possibilidade inscrita em sua própria estrutura -, também a sexualidade não se distingue completamente da existência, não se oferece como recusa ou mesmo como latência. Entre elas, o que opera é uma estrutura comum, "típica" ou fisionomia constante, em relação à qual ambas versam, que cada uma exprime a seu modo, e que, por isso mesmo, ao invés de se dissipar nelas, nelas se reafirma, revelando-as como horizontes por ela própria abertos: 
Da mesma maneira a sexualidade, sem ser o objeto de um ato de consciência expresso, pode motivar as formas privilegiadas de minha experiência. Assim considerada, quer dizer, como atmosfera ambígua, a sexualidade é coextensiva à vida. Dito de outra maneira, o equívoco é essencial à existência humana e tudo o que vivemos ou pensamos sempre tem vários sentidos (MERLEAU-PONTY, 1996, p. 233).

Retomando o que já nos ensinavam as descrições anteriores, o que as descobertas de Freud revelam, mais do que a permanência de um pensamento objetivo ou dual, é precisamente a "equivocidade" intrínseca à condição humana, sua possibilidade constitutiva de dilatar-se e des-identificar-se. Há, como afirma a Fenomenologia da percepção, um "princípio de indeterminação" na existência (MERLEAU-PONTY, 1996, p. 234), não por qualquer tipo de "falha", mas precisamente pela dimensão de abertura e de transcendência inscrita em seu funcionamento relacional, sempre polarizada em direção ao que não é ela, ${ }^{24}$ sem com isso implicar o retorno a uma forma qualquer de inconsciente separado ou de ruptura no interior da consciência. É isso que faz com que nos pareça possível reafirmar uma hipótese que já a Estrutura do comportamento nos permitia formular a respeito do modo pelo qual Merleau-Ponty recorre a Freud em suas primeiras obras, em um movimento que parece realizar-se simultaneamente como "recusa" e como deslocamento da noção de inconsciente: é ao lado da existência, e de sua indeterminação intrínseca, que é preciso situá-lo, não como o "não manifesto" ou o "latente", mas como a distensão originária que sustenta a experiência, dimensão intrínseca ao caráter dissonante e referencial da estrutura. Assim compreendido, ele deixa de ser o avesso da consciência, para revelar-se operante nela própria, tão logo assumida em sua equivocidade originária: o "inconsciente" não é seu duplo ou sua negação, mas seu alargamento.

Assim, recuperando a problemática circunscrita no início deste artigo, discordamos da leitura que parte dos autores advindos da psicanálise endereça ao autor, sobretudo porque ela ignora esse caráter estrutural e diacrítico que centra suas descrições, desconsiderando a recompreensão dos termos proposta por sua filosofia. $\mathrm{O}$ inconsciente descrito por Merleau-Ponty não é o desdobramento de um corpo e de um sensível concebidos em termos de positividade, mas uma dimensão estrutural de uma experiência originariamente aberta e equívoca, em que a suposição implícita de um dualismo de princípio - seja para afirmar sua "fratura" ou sua "continuidade" - torna-se desprovida de sentido. É por isso que, em termos merleau-pontyanos, recusar a ruptura não implica afirmar a continuidade, pois operar no interior dessa alternativa é já aceitar, conscientemente ou não, o pensamento objetivo e suas noções alternativas. E é justamente o reconhecimento da possibilidade de ultrapassar essa lógica dual que o aproxima de Freud e orienta sua leitura. Nesse sentido, talvez pudéssemos supor, curiosamente, que, para defender-se da crítica recebida por parte da herança da psicanálise, seria ao próprio Freud que o filósofo recorreria.

\section{BIBLIOGRAFIA}

AYOUCH, T. (2012). Merleau-Ponty e a psicanálise: da fenomenologia da afetividade à figurabilidade do afeto. Jornal de Psicanálise 45 (83), 173-190.

BONAN, R. (2005). Merleau-Ponty de la perception à l'action. Marseille: PUP.

. (s.d.) La dimension commune: le problème de l'intersubjectivité dans la philosophie de Merleau-Ponty. Paris: L'Harmattan, v. 1.

(2001). La dimension commune: l'institution intersubjective comme poétique gé-

nérale. Paris: L’Harmattan, v. 2. 
CASTORIADIS, C. (1997). Fait et à faire. Paris: Seuil.

DASTUR, F. (2001). Chair et langage. La Versanne: Encre Marine.

GREEN, A. (1973). Le discours vivant. Paris: PUF.

LACAN, J. (2008). Seminário, livro 11: os quatro conceitos fundamentais da psicanálise. Rio de Janeiro: Zahar.

$$
\text { . (2001). Autres écrits. Paris: Seuil. }
$$

LEFORT, C. (1978). Sur une colonne absente. Écrits autour de Merleau-Ponty. Paris: Gallimard.

HUSSERL, E. (1988). Idées directrices pour une phénoménologie et une philosophie phénomélogique pures. Trad. Éliane Escoubas. Paris: PUF.

. (1976). La crise des sciences européenes et la phénoménologie transcendantale. Trad.

Gérard Granel. Paris: Gallimard.

MERLEAU-PONTY, M. (1975). A dúvida de Cézanne. São Paulo: Editora Abril (Os Pensadores). . (1994). Fenomenologia da percepção. Trad. Carlos Alberto Ribeiro de Moura.

São Paulo: Martins Fontes. . (1967). La Structure du Comportement. Paris: PUF.

. (1996). Le primat de la perception et ses conséquences philosophiques. Lagrasse:

Verdier.

. (1964). Le Visible et le Invisible. Paris: Gallimard.

. (2003). L'institution. La passivité. Paris: Belin.

. (1964). L'Oeil et L'Esprit. Paris: Gallimard.

. (1988). Merleau-Ponty à la Sorbonne - Résumés de Cours: 1948-1952. Grenoble:

Cynara.

. (1997). Sens et Non-Sens. Paris: Gallimard.

. (2003). Signes. Paris: Gallimard.

MOURA, C. A. R. (2001). Racionalidade e crise. São Paulo: Discurso Editorial; Edufpr.

PONTALIS, J. (1993). Après Freud. Paris: Gallimard.

RODRIGO, P. (2002). Merleau-Ponty et la psychanalyse. In: Chiasmi International. Paris: Vrin, p. 27-48. 


\section{NOTAS}

1. A esse respeito ver, sobretudo: LACAN, Autres écrits. Paris: Seuil, 2001.

2. Ayouch, em seu artigo, enfatiza a descrição do inconsciente como ausência total do sentido.

3. "Estas quatro críticas se endereçam à negligência por Merleau-Ponty da divergência central entre os modos de funcionamento da consciência e do inconsciente. A continuidade e a indivisão que o filósofo coloca entre a consciência e o inconsciente é diametralmente oposta ao corte, à ruptura e à barra instituída pela psicanálise entre os dois sistemas" (AYOUCH, 2012, p. 180).

4. Ayouch, em seu artigo, chega a afirmar a afirmar que, para o filósofo, o inconsciente é o invisível.

5. É significativo, nesse sentido, que as leituras acima pareçam não levar em conta que a noção de corpo, em Merleau-Ponty, é inconcebível sem a noção de estrutura, sem a lógica de horizontes e sem a relação de figura e fundo. Compreensão que é amplamente discutida e explicitada pelo filósofo tanto em A estrutura do comportamento quando na Fenomenologia da percepção.

6. Nesse sentido, cabe notar o número significativo de estudos que tratam da relação que o pensamento mais tardio de Merleau-Ponty mantém com a psicanálise. Apenas como exemplo, podemos mencionar as discussões de BONAN (2005) e de RODRIGO (2002) sobre a relação entre a noção de "carne" e as discussões do autor com o pensamento psicanalítico.

7. Por termos proposto essa delimitação, não entraremos, aqui, na discussão empreendida pelo filósofo a respeito da linguagem e do simbólico, mas é importante mencionar que, também eles, dificilmente permitiriam permanecer intactas as afirmações de Ayouch e dos demais psicanalistas por ele mencionados.

8. Nesse sentido, procuramos sustentar que as leituras sobre o inconsciente em Merleau-Ponty teriam que considerar o projeto mais amplo de sua filosofia de proposição de uma noção própria de estrutura, de reformulação do estatuto da consciência e, por sob elas, de recompreensão da negatividade, elementos fundamentais para que suas descrições possam ser efetivamente mensuradas.

9. A noção de estrutura, central em toda a reflexão do filósofo, será aqui abordada principalmente através daqueles seus aspectos mais intimamente relacionadas à questão proposta.

10. Esse movimento, o recurso à percepção como "solo" capaz de escapar aos dualismos construídos pela tradição, será recorrente ao longo de toda a sua obra.

11. Já há aqui, portanto, uma referência à questão da abertura e da intersubjetividade como traços originários do sujeito e da consciência. Sobre o tema da intersubjetividade, Bonan desenvolve um detido e aprofundado estudo: BONAN, L'institution intersubjective comme poétique générale, v. 1, 2. L'Harmattan, 2001.

12. Essa é uma das razões que explicam o porquê da crítica de Merleau-Ponty a ele transitar, como procuraremos mostrar, entre o afastamento e a aproximação.

13. Como veremos adiante, a descrição das patologias ocupa um importante papel na Fenomenologia da percepção.

14. Dado o caminho aqui proposto, não nos deteremos propriamente no tema da expressão, mas cabe ressaltar que ele tem um papel central na reflexão do filósofo.

15. O texto de Valéry citado por Merlau-Ponty é Introduction à la Methode, de Léonard de Vinci. 
16. O texto de Freud citado por Merlau-Ponty é Un Souvenir d'Enfance, de Léonard de Vinci.

17. Cabe destacar que são muitos os caminhos oferecidos pela Fenomenologia da percepção para se descrever o estatuto da consciência e, por isso mesmo, também do inconsciente, sobretudo pela ênfase na dimensão de abertura e no caráter relacional inscritos na existência. Poderíamos, nesse sentido, percorrer, por exemplo, as possibilidades abertas pelas descrições da percepção, da expressão, da temporalidade, entre outros. É por essa razão que, uma vez mais, é necessário um recorte. Devido ao caminho que seguimos até aqui, e devido às referências mais explícitas a Freud, optamos por nos concentrar nas discussões sobre a patologia e a sexualidade. É importante notar, contudo, que, de acordo com o estilo próprio da filosofia merleau-pontyana, cada tema acaba por envolver, ainda que indiretamente, os demais, não sendo possível - nem recomendável - fazer uma leitura estanque ou inteiramente fechada, de modo que algumas questões próximas acabarão sendo também apontadas.

18. Esse tema e essa compreensão são amplamente trabalhados pelo filósofo, especialmente em suas primeiras obras.

19. De acordo com a compreensão do autor sobre a estrutura, discutida acima.

20. Essa questão é trabalhada em praticamente todos os momentos da obra do autor.

21. Essa questão é amplamente descrita e trabalhada pelo autor tanto em A estrutura do comportamento quanto na Fenomenologia da percepção.

22. Como mostra, por exemplo, a descrição do sonho, em que o sentido sexual não é designado pelo "simbólico", mas o símbolo ou a imagem tornam-se eles próprios a significação (MERLEAU-PONTY, 1975, p. 233).

23. Como mostra, por exemplo, a impossibilidade de se dissociar o erótico do existencial, os setores das funções (MERLEAU-PONTY, 1975).

24. É o que confirma a possibilidade de distinção, em termos existenciais, entre uma experiência verdadeira e uma experiência falsa. A possibilidade de um amor falso - não dissimulado, mas efetivamente vivido - mostra que a suposição de uma plena posse de si, de um saber prévio que fundaria a verdade, oblitera um fenômeno mais originário e constitutivo, uma vez que o sentimento equivocado, a despeito do que supõe o intelectualismo, é de fato assumido e incorporado como tal, fazendo-se situação concreta para o sujeito. Em contrapartida, a ideia de que esse sentimento seria ignorado pelo sujeito, figurando em um inconsciente que operaria nele sem que ele o soubesse, também é recusada, uma vez que era o sujeito quem vivia sua existência mobilizada, reconfigurando e retraçando seu campo existencial no diálogo com outrem. O amor vivido, e ainda não tematizado, não é nem uma deliberação posta pelo sujeito, uma decisão da consciência, e nem um "conteúdo" inconsciente que operaria nele à sua revelia, uma causa determinada. Ao contrário, ele é a "polarização existencial” pela qual o sentimento reconfigura as relações do sujeito e de seu entorno: "O amor que prossegue sua dialética através de mim e que acabo de descobrir não é, desde o início, uma coisa escondida em um inconsciente, e também não é um objeto diante de minha consciência, ele é o movimento pelo qual me voltei para alguém, a conversão de meus pensamentos e de minhas condutas - eu não o ignorava, já que era eu quem vivia horas de tédio antes de um encontro e que sentia alegria quando ele se aproximava, ele era do começo ao fim vivido, ele não era conhecido” (MERLEAU-PONTY, 1994, p. 509). 